\title{
A Note on the Role of Social Impact Investments in Minimum Variance Portfolios
}

\author{
Massimo Biasin ${ }^{1}$, Roy Gerqueti ${ }^{2,3,4}$, Emanuela Giacomini ${ }^{1}$, Nicoletta Marinelli ${ }^{1}$, \\ Anna Grazia Quaranta ${ }^{1}$ and Luca Riccetti ${ }^{1, *}$

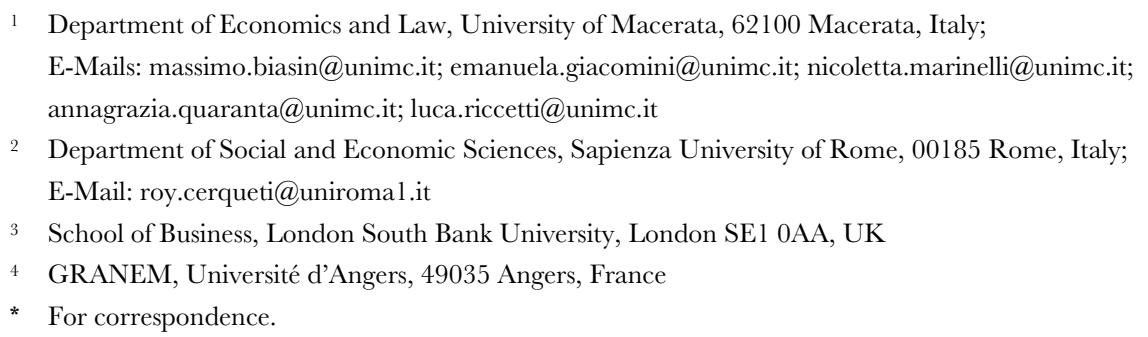

Abstract This paper explores a possible way in which strategic asset allocation decision-making processes can suitably exploit Social Impact Investments (SIIs). We focus on the role that SIIs play in the context of variance-minimizing investments. To this aim, we employ an index that tracks companies' financial performance. A hand-collected sample of Social Impact Firms (SIFs) is the basis of the empirical experiments. Our results point out that, on average, investors should invest a relevant fraction of their wealth in stocks of SIFs.

Keywords social impact investments; asset allocation; minimum variance

JEL Classification: G1 1; G17; G23; C0

\section{Introduction}

During the last decades, the notion of "doing well and doing good" has become an attractive proposition for private and institutional investors. Different strategies could be used in order to select investments that reconcile environmental and social purposes with their financial goals. Among the possible investment alternatives, Social Impact Investments (SIIs) are increasingly important around the world. According to the IFC [1], at the end of 2020 there were $\$ 636$ billion in assets invested in SIIs across the globe, both publicly (\$349) and privately (\$286) managed, an increase of $26 \%$ over 2019 . The number of investment vehicles is continuously growing reaching 1001 (private) impact funds (2020), increasing the investment opportunities. The market is expected to grow further as a consequence of the global pandemic crisis and the related social and economic concerns (GIIN [2]). Similar to Socially Responsible Investments (SRIs), SIIs focus on investments that create additional value for both shareholders and the whole society. However, SIIs go beyond this proposition as they focus on investments that deliberatively address one or more social and environmental issues (such as creating employment for the socially disadvantaged, protecting the environment, etc.) in order to make a positive and measurable social impact.

While the rapid growth of the SIIs market demonstrates that investors are becoming more aware of its potential and want to make a difference by choosing specific categories of investments, the research in this field is quite limited and primarily refers to the risk-return profiles of SRI stocks or mutual funds compared to conventional investments (among others, [3-6]). Only recently, few papers investigate the risk-return characteristics of SII providing mixed evidence. Precisely, Barber et al. [7] find that impact investors consciously accept lower financial returns in exchange for positive societal externalities; in contrast, Jeffers et al. [8] show that impact funds perform on par with matched non-impact funds.

Investments that apply ethical and moral screens to stock selections have become increasingly relevant over the last decade also in the context of strategic asset allocation decision-making processes. Surprisingly, very few papers focused on whether the optimal portfolio allocation should include also SIIs. The Asset Allocation Working Group of the G8 Social Impact Investment 
Taskforce (AAWG [9]) conclude that by including an impact allocation, investors may achieve the same financial return while improving portfolio diversification, at the cost of some increase in illiquidity. La Torre et al. [10] show that non-impact portfolios have higher Sharpe ratios (Sharpe [11]) than SIIs portfolio. Biasin et al. [12] compare the out-of-sample results for portfolios including or not the SIIs among the feasible assets, and find that the optimal portfolios should include a large portfolio percentage of SIIs.

While Biasin et al. [12] find supporting evidence to the hypothesis that SIIs can improve portfolio risk-return performance, in this paper we look at whether SIIs can also play a role in the asset allocation of investors that are particularly risk-averse. Indeed, the dramatic decline of global stock market capitalization indices during the 2007-2008 financial crisis had come with unseen volatility that was several times higher in the end of 2008 compared to historical figures. Such a turbulent situation greatly decreased investors' appetite for risk and forced market participants to seek for defensive strategies that are less vulnerable to the market turmoil. Moreover, Haugen and Baker [13], Clarke, Silva, and Thorley [14], and Poullaouec [15] find that investment strategies that are targeted at reducing portfolio risk demonstrated returns similar to their benchmark capitalization weighted indices but with 25-30\% lower standard deviation. Therefore, it comes as no surprise that minimum portfolio risk strategy has remarkably drawn attention and an increasing number of index and investment funds that use those investment approaches have been launched after the 2007-2008 financial crisis (see among others, [13-17]).

We believe that SIIs could be a suitable asset class for investors looking for minimizing their portfolio risk because of the potential low correlation with other traditional asset classes. Indeed, Social Impact Firms (SIFs hereafter) often relate to a-cyclical sectors (such as the environmental sector) or counter-cyclical sectors (such as sectors related to social needs, which are usually more relevant during downturn phases of the business cycle). Therefore, SIFs could be very valuable for those investors seeking downside risk protection in their portfolio.

To test our hypothesis, we use a dataset of 50 firms that could be effectively classified as SIIs (as in Biasin et al. [12]) to construct portfolios that aim to minimize portfolio risk, evaluated in terms of portfolio variance.

Our work contributes to the literature on the impact of alternative asset classes in portfolio strategies that aim to minimize risk. Indeed, to the best of our knowledge, this is the first paper that evaluates the role of SIIs in minimum risk portfolios. We contribute to this literature by showing that investors with a low appetite for risk should invest in stocks of SIFs as long as their aim is to obtain the minimum variance portfolio.

This article proceeds as follows. Next section briefly describes the dataset and the empirical research methods. Section 3 analyses and presents the results of the study. Section 4 concludes with recommendations and suggestions for further studies.

\section{Data and Methodology}

As in Biasin et al. [12], we rely on independent and publicly available criteria provided by the OECD [18] to define SIIs. The OECD differentiates SIIs from conventional investments by identifying some attributes ${ }^{1}$ :

1) Social Target Areas: they primarily refer to eight core eligible areas (Ageing, Disability, Health, Children and Families, Public order and Safety, Affordable Housing, Unemployment, Education and Training) with the consideration of five other areas (Agriculture, Environment and Energy, Water and Sanitation, Financial Services-Microfinance and ICT), whose inclusion depends on the other characteristics of the investments described below;

2) Beneficiary Context: the company is required to operate in order to fulfil the needs of populations at risk or those living in underserved or developing areas. In this regard, if the area of business of a company is not among those that are considered as core Social Target Areas, but provides a benefit to a population that is at risk, then it could be considered as SIIs;

3) Degree of Publicness: it relates to the type of good or service provided by the company and requires that goods or services eligible for SIIs lie within the continuum between the two boundaries (public and private). Indeed, social goods have different characteristics than pure private or

\footnotetext{
1 The OECD framework includes two additional requirements (i.e., Investor intent and Return expectation), but they refer primarily to the investor rather than to the investee. Therefore, we exclude them as they fall outside the scope of our analysis. See OECD (2015).
} 
public goods insofar as they would not completely exclude benefits accruing to non-target beneficiaries;

4) Delivery Organization Intent: it deals with a verifiable demonstration of the firm's social intent and requires that the delivery organisation must put sufficient effort into demonstrating that they are committed to the social cause. A strong level of commitment can be demonstrated, for instance, through: (i) some form of compulsory reporting of social outcomes to shareholders within the organisation's statutes; (ii) an external Certification or Label and (iii) legally binding constraints, which provide the strongest indication of commitment to social goals;

5) Measurability of Social Impact: it refers to the fact that a firm that does not have any form of social impact measurement cannot be considered SIIs. The assessment of the impact of the investments can be qualitative or quantitative.

To select our sample of firms that could be effectively targeted by SIIs, we started out with the full list of firms reported on wikipositive.org at the end of 2018, a public portal for social and environmental research sharing database of enterprises that (to some degree) proactively strive to make a positive impact. Out of the wikipositive.org database, we selected those firms that were compliant with at least four out of the five criteria outlined in OECD [18]. The analysis of the abovementioned SII criteria was conducted using various sources of information, including company's webpage, article of association, and financial statements. We require each firm to be listed on a stock exchange because we need the time series of stock prices for the empirical analysis. Overall, these criteria lead us with a final sample of 52 SIFs across the globe.

We gathered from Thomson Reuters Datastream closing prices, market capitalizations and free float rates for each SIF included in the sample as well as the total return of the Morningstar Global Government Bond Index USD (MGGBI) and MSCI All Country World Index (ACWI) on a daily basis. As explained in Biasin et al. [12], we used the MSCI All Country World Index (ACWI) as a global stock market benchmark, because it takes into account all the countries issuing securities belonging to our sample of SIFs, including both developed and emerging markets (23 developed and 24 emerging markets). Indeed, the ACWI is a market capitalization weighted index designed to provide a broad measure of equity-market performance throughout the world. The period taken into consideration in the analysis started from January 2002 and finished at the end of September 2018.

Next, we construct our Social Impact Finance Stock Index (SIFSI hereafter) by using the daily total return index of the selected SIFs. Although we started out with 52 possible constituents, we deleted two of them because their price series were overly lacking (see Appendix A for a complete list of the firms).

Given the different time of entry in the stock market of each constituent, we followed one of the two MSCI methodologies to update the indices. In particular, we choose the ongoing eventrelated changes in which changes are implemented in the indexes as they occur; more specifically, significantly large IPOs are included in the indexes after the close of the company's 10th day of trading. We decided to follow this methodology for all of our securities (also for small IPOs). Therefore, in order to achieve a greater overlap with the ACWI methodology, we excluded the first 10 days of listing after the IPO. This choice allowed us to make the securities available in the index as soon as possible, thus increasing the descriptive capacity of the index ${ }^{2}$.

We construct minimum variance portfolios following Markowitz mean-variance optimization methodology. Generally speaking, this methodology allows to determine the optimal portfolio weights in the set of efficient portfolios which guarantee the lowest level of risk for a given expected level of return. In this perspective, the minimum variance portfolio represents a specific optimal portfolio, which possesses the smallest variance among all portfolios on the efficient frontier.

Markowitz obtained the goal by passing through a significant sub-set that exploits the condition that the mean has a positive effect on utility while the variance does not.

As a result, in formal terms, in relation to $n$ risky assets $(i=1, \ldots, n)$, for a given return level $m$, an investor will have to solve the following constrained quadratic minimization subproblem:

\footnotetext{
2 The calculation method of the ACWI imposes that once $99 \%$ of the market capitalization is reached, smaller securities are excluded from the index. However, to avoid a reduction in the number of constituents of SIFSI, we decided not to apply this rule.
} 


$$
\left\{\begin{array}{c}
\min _{w} \frac{1}{2} \mathbf{w}^{\prime} \boldsymbol{\Sigma} \mathbf{w} \\
\mathbf{w}^{\prime} \boldsymbol{\mu}=\mathrm{m} \\
\mathbf{1}^{\prime} \mathbf{w}=1
\end{array}\right.
$$

where $\mathbf{w}$ is the vector of the (optimal) weights, $\boldsymbol{\Sigma}$ is the assets return variance- ${ }^{-}$covariance (symmetric and positive definite) matrix, $\mathbf{w}^{\prime} \mathbf{\Sigma} \mathbf{w}$ is the portfolio variance, $\boldsymbol{\mu}$ contains the expected returns of each asset and $\mathbf{w}^{\prime} \boldsymbol{\mu}$ is the portfolio expected return.

The solution of the problem is

$$
\mathbf{w}=\frac{\mathrm{C}-\mathrm{mB}}{\Delta} \boldsymbol{\Sigma}^{-\mathbf{1}} \mathbf{1}+\frac{\mathrm{mA}-\mathrm{B}}{\Delta} \boldsymbol{\Sigma}^{-\mathbf{1}} \boldsymbol{\mu}
$$

where

$$
\mathrm{A}=\mathbf{1}^{\prime} \boldsymbol{\Sigma}^{-\mathbf{1}} \mathbf{1}>0 ; \mathrm{B}=\mathbf{1}^{\prime} \boldsymbol{\Sigma}^{-\mathbf{1}} \boldsymbol{\mu} ; \mathrm{C}=\boldsymbol{\mu}^{\prime} \boldsymbol{\Sigma}^{-\mathbf{1}} \boldsymbol{\mu}>0 ; \Delta=\mathrm{AC}-\mathrm{B}^{2}>0
$$

This portfolio corresponds to the fully-risk averse investor who aims to minimize the variance. The relevance of minimum variance portfolio in financial applications was well supported by Merton [19] who underlined that the estimates of the variances and covariances of the asset returns are much more accurate than the estimates of the means.

\section{Empirical Results}

In the empirical analysis, we consider the daily returns for the three international indexes previously introduced (MGGBI, ACWI, and SIFSI) for the reported period. The expected returns and variance are computed using a rolling windows-based estimation from historical daily data, which are exponentially weighted and observed for the past 2000 days. The choice to use this time span - wider than those generally applied in portfolio selection problems - certainly allows obtaining adequate parameters' value to be included in the model. Indeed, they result from considering a large number of situations, which occurred in the past and are reasonably possible in the future. The optimization process is simple in that no constraints are imposed except the restrictions that individual security weights are positive (long-only constraints) and sum to $100 \%$ (full investment constraint). To solve the optimization problem, we run the "Portfolio" object in the Matlab Financial Toolbox since it precisely supports the Markowitz mean-variance portfolio optimization.

Figure 1 shows the asset allocation of minimum variance portfolios, and it allows us to observe the changes in the asset allocation of minimum variance portfolios about every 10 months from November 2010 to September 2018.

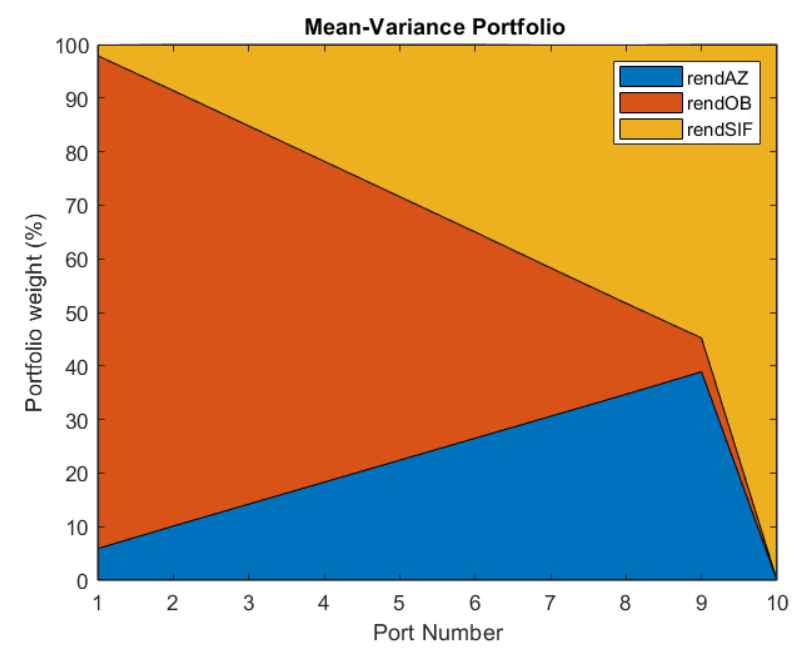

Figure 1. Weights of the minimum variance portfolios.

We observe that the fixed income index (MGGBI) receives the largest weight on average, equal to $44.26 \%$. However, its weight tends to reduce overtime and it is equal to zero in the last period. This result seems consistent with our expectation and previous studies that find that individuals tended to shift their financial assets towards bonds rather than stocks right after the 
financial crisis. Indeed, at the beginning of our sample period (from 2010 to 2013), the stock market faced unseen uncertainty and low returns mainly due to the 2007-2008 financial crisis and the 2010 European sovereign debt crisis. Consequently, investors started to increase the weight of bonds in their asset allocation when minimizing portfolio variance.

However, in the following periods, when the stock market recovered the asset allocation was rebalanced towards the equity component and, more precisely, in favour of SIFs.

Interestingly, in the last period the minimum variance portfolio invests only in the SIFSI index, which receives the $100 \%$ of the invested wealth. The SIFSI index is the only one that is always included in all the 10 portfolio allocations, and its average weight is very high (equal to $35.58 \%$ ), confirming the importance of this asset class in the perspective of risk minimization relative to the market stock index (MSCI ACWI) that receives much lower weight on average (equal to $20.16 \%$ ).

\section{Conclusions}

This paper contributes to the literature that investigates how social impact investments can be drivers of asset allocation by assessing its role in minimum risk portfolios. Following Biasin et al. [12], we construct an index that tracks the performance of firms that could be effectively targeted by SIIs to analyse whether investors that aim towards minimizing portfolio risk should invest in this novel asset class. We find that investing in social impact firms is important when investors seek for minimum variance portfolios. Our finding has significant implications given the documented risk aversion among market participants, especially as consequence of the current COVID-19 pandemic crisis, and the growing interest of institutional investors towards applying this kind of optimization strategy. Indeed, many institutional investors are evaluated also on risk-adjusted performance measures, such as the Sharpe Ratio, which uses the standard deviation to adjust the performance measure.

Furthermore, we show that the ethically-grounded investments present a relevant economic meaningfulness as risk-minimizers, beyond the intuitive positive aspect of fostering social impact targets. This outcome can be of real interest for practitioners, who can observe the level of social business targets of the companies as a proxy of the financial efficiency for investment strategies.

We leave for future research the challenging theme of testing other risk measures to assess how the properties of the considered risk measures could affect the outcomes of this study, and how these optimization strategies relate to macroeconomic variables.

\section{Funding}

This work was supported by Ministero dell'Istruzione, dell'Università e della Ricerca italiano (MIUR), project "Una piattaforma italiana per la finanza d'impatto: modelli finanziari per l'inclusione sociale ed un welfare sostenibile" (SIF16_00055).

\section{Author Contributions}

Conceptualization: all authors; Data curation: M.B., E.G., N.M. and L.R.; Formal analysis: A.G.Q.; Funding acquisition: N.M.; Investigation: A.G.Q. and L.R.; Methodology: R.G., A.G.Q. and L.R.; Project administration: all authors; Resources: E.G.; Software: A.G.Q.; Supervision: all authors; Validation: all authors; Visualization: A.G.Q.; Writing - original draft: all authors; Writing - review \& editing: all authors.

\section{Conflicts of Interest}

The authors declare no conflict of interest.

\section{References}

1. Investing for Impact: The Global Impact Investing Market 2020. Available online: https://www.ifc.org/ wps/wcm/connect/publications_ext_content/ifc_external_publication_site/publications_listing_page/impactinvesting-market-2020 (accessed 4 February 2022).

2. The Impact Investing Market in the COVID-19 Context: An Overview. Available online: https://thegiin.org/ research/publication/the-impact-investing-market-in-the-covid-19-context-an-overview (accessed 31 January 2022).

3. Adler, T.; Kritzman, M. The Cost of Socially Responsible Investing. The 7. Portf. Manag. 2008, 35, 52-56. https://doi.org/10.3905/JPM.2008.35.1.52

4. Almazan, A.; Brown, K.C.; Chapman, D.; Carlson, M. Why constrain your mutual fund manager? f. Financ. Econ. 2004, 73, 289-321. https://doi.org/10.1016/j.jfineco.2003.05.007 
5. Bello, Z.Y. Socially responsible investing and portfolio diversification. The f. Financ. Res. 2005, $28,41-57$. https://doi.org/10.1111/j.1475-6803.2005.00113.x

6. Renneboog, L.; Horst, J.T.; Zhang, C. Socially responsible investments: Institutional aspects, performance, and investor behavior. F. Bank. Financ. 2008, 32, 1723-1742. https://doi.org/10.1016/j.jbankfin.2007.12.039

7. Barber, B.M.; Morse, A.; Yasuda, A. Impact investing. F. Financ. Econ. 2021, 139, 162-185. https://doi.org/ 10.1016/j.jfineco.2020.07.008

8. Jeffers, J.; Lyu, T.; Posenau, K. The Risk and Return of Impact Investing Funds. In Proceedings of the 19th Paris December Finance Meeting, Paris, France, 16 December 2021. http://doi.org/10.2139/ssrn.3949530

9. Allocating for Impact. Subject Paper of the Asset Allocation Working Group of the Social Impact Investment Taskforce established. Asset Allocation Working Group, Bridges Fund Management: London, UK, 2014.

10. La Torre, M.; Chiappini, H.; Mango F. Do Impact investments contribute to portfolio performance? A preliminary Investigation. 7. Bus. Econ. 2017, 8, 249-259.

11. Sharpe, W.F. A Simplified Model of Portfolio Analysis. Manag. Sci. 1963, 9, 277-293.

12. Biasin, M.; Cerqueti, R.; Giacomini, E.; Marinelli, N.; Quaranta, A.G.; Riccetti, L. Macro Asset Allocation with Social Impact Investments. Sustainability 2019, 11, 3140. https://doi.org/10.3390/sul 1113140

13. Haugen, R.A. Baker, N.L. The efficient market inefficiency of capitalization-weighted stock portfolios. The f. Portf. Manag. 1991, 17, 35-40. https://doi.org/10.3905/jpm.1991.409335

14. Clarke, R.; Silva, H.; Thorley, S. Minimum-Variance Portfolios in the U.S. Equity Market. The 7. Portf. Manag. 2006, 33, 10-24. https://doi.org/10.3905/jpm.2006.661366

15. Poullaouec, T. Things to consider when investing in minimum variance strategies. State Street Global Advisors, 2008.

16. Appel, D. Low volatility, high return strategies get a look, Pensions and Investments. Available online: https://www.pionline.com/article/20081103/ONLINE/81 1039995/low-volatility-high-return-strategies-get-alook (accessed 4 February 2022).

17. Keefe, J. How to play safe before the Next Big Thing. The Financial Times 4 Aprial 2008.

18. Social Impact Investment, Building the Evidence Base. Organisation for Economic Co-operation and Development (OECD), Paris, France, 15 December 2015.

19. Merton, R.C. On estimating the expected return on the market: an exploratory investigation. F. Financ. Econ. 1980 8, 323-361. https://doi.org/10.1016/0304-405X(80)90007-0 
Appendix A

Table A1. List of social impact firms.

\begin{tabular}{|c|c|c|}
\hline Name & Social Investment Areas & Gountry of Incorporation \\
\hline$\overline{\mathrm{UCB}}$ & Health & Belgium \\
\hline Sunopta & Agriculture & Canada \\
\hline Boralex & Environment and Energy & Canada \\
\hline Cascades, Inc. & Environment and Energy & Canada \\
\hline Trina Solar & Environment and Energy & China \\
\hline Yingli Green Energy & Environment and Energy & China \\
\hline Novo Nordisk AS & Health & Denmark \\
\hline Fortum OYJ & Environment and Energy & Finland \\
\hline Centrotec Sustainable Ag & Environment and Energy & Germany \\
\hline Steico AG & Environment and Energy & Germany \\
\hline Torishima Pump Mfg & Environment and Energy & Japan \\
\hline Sekisui House & Housing & Japan \\
\hline Kurita Water Industries & Water and Sanitation & Japan \\
\hline Manila Water Company & Water and Sanitation & Philippines \\
\hline African Bank Investments & Financial Services & South Africa \\
\hline Acciona NA & Environment and Energy & Spain \\
\hline EDP Renovaveis & Environment and Energy & Spain \\
\hline Iberdrola Renovables & Environment and Energy & Spain \\
\hline Mosel Vitelic & Environment and Energy & Taiwan \\
\hline Motech Industries & Environment and Energy & Taiwan \\
\hline Accsys Technologies & Environment and Energy & United Kingdom \\
\hline Ashley House & Health & United Kingdom \\
\hline Assura & Health & United Kingdom \\
\hline Capital for Colleagues & Education and Training & United Kingdom \\
\hline Catenae Innovation & ICT & United Kingdom \\
\hline Gity Windmills & Environment and Energy & United Kingdom \\
\hline Good Energy Group & Environment and Energy & United Kingdom \\
\hline Halosource & Water and Sanitation & United Kingdom \\
\hline Menhaden Capital & Environment and Energy & United Kingdom \\
\hline Obtala & Agriculture & United Kingdom \\
\hline Surepure & Water and Sanitation & United Kingdom \\
\hline Augean PLC & Environment and Energy & United Kingdom \\
\hline AstraZeneca PLC & Health & United Kingdom \\
\hline Shire Ltd & Health & United Kingdom \\
\hline Smith \& Nephew & Health & United Kingdom \\
\hline Solazyme & Agriculture & United States of America \\
\hline United Natural Foods & Agriculture & United States of America \\
\hline Corrections Corp of America & Education and Training & United States of America \\
\hline Res-Care & Education and Training & United States of America \\
\hline Eco-safe Systems USA & Environment and Energy & United States of America \\
\hline First Solar, Inc. & Environment and Energy & United States of America \\
\hline International Paper Company & Environment and Energy & United States of America \\
\hline Ocean Power Technology & Environment and Energy & United States of America \\
\hline Schnitzer Steel Industries & Environment and Energy & United States of America \\
\hline SunPower Corporation & Environment and Energy & United States of America \\
\hline Waste Management & Environment and Energy & United States of America \\
\hline Bodisen Biotech & Environment and Energy & United States of America \\
\hline Moser Baer India & Environment and Energy & United States of America \\
\hline Cephalon & Health & United States of America \\
\hline Philippine Long Distance Tel. Comp. & ICT & United States of America \\
\hline Kenexa Corp & ICT & United States of America \\
\hline Tetra Tech Inc & Water and Sanitation & United States of America \\
\hline
\end{tabular}

